\title{
Research on the Influence Mechanism of Block Chain on the Credit of Transportation Capacity Supply Chain Finance
}

\author{
Lili Xu (D), Yubin Yang (D), and Xuejian Chu \\ School of Management, Shanghai University, Modern Logistics Research Center, 5th Floor, Third Teaching Building, \\ 149 Yanchang Road, Shanghai, China \\ Correspondence should be addressed to Yubin Yang; ericalili@163.com
}

Received 27 May 2021; Revised 20 September 2021; Accepted 6 November 2021; Published 30 November 2021

Academic Editor: Arunava Majumder

Copyright (C) 2021 Lili Xu et al. This is an open access article distributed under the Creative Commons Attribution License, which permits unrestricted use, distribution, and reproduction in any medium, provided the original work is properly cited.

This paper aims at the promotion of the application of inclusive financing into transportation capacity financing by combining transportation capacity supply chain with block chain technology as a brand-new financing topic. It focuses on the influencing mechanism by block chain on credit access, credit line, and credit supervision. From the perspective of "transportation" finance, the application of block chain in different scenarios is demonstrated after analyzing the attenuation process of credit transmission in the supply chain, the reviewing of two credit line evaluation methods of business self-compensation and credit guarantee, and the reviewing of regulatory requirements in transaction closed-loop, delivery closed-loop, and capital closed-loop; therefore the 3 major influencing mechanisms by block chain on the transportation capacity supply chain financing credit granting are discovered, indicating the effective improvement of financial institutions participation and better credit line for the financing of micro, medium, and small transportation enterprises (SMEs) by the application of block chain technology.

\section{Introduction}

According to the data by the Financial Commission of China Federation of Logistics \& Purchase, the overall annual loan financing demand by domestic logistic enterprises exceeds 3000 billion, where only nearly $10 \%$ are met by banks. The annual financing demand for freight advance payment alone exceeds 600 billion yuan, where only nearly $5 \%$ are met by banks. In transportation capacity supply chain market, $68.82 \%$ of actual carriers are middle and small sized enterprises whether independent or affiliated, featuring smaller size, short collateral, imperfect financial system, absence of substantial finance, and market risk vulnerabilities. Core enterprises in supply chain are introduced into supply chain finance (SCF) so the credit advantages and resource endowment could be taken as risk control factors; based on the predictable future cash flows the low-cost financing service could be provided to the upstream and downstream SMEs in supply chain for closed clearance and credit granting, etc., so the difficulties and high cost for SMEs in SCF could be alleviated.
However, the traditional SCF mainly serves the neighboring upstream and downstream of the core enterprises while the credit of the core enterprises cannot be delivered and remains inaccessible to the SMEs lying in tail end of supply chain; also the authenticity of enterprise transactions cannot be proved, resulting in the application of inclusive finance remaining substantially restrained. In the context of the new economy, SCF based on block chain and other technologies is regarded as the next hot topic, with the number of block chain enterprises growing and application of block chain in SCF extending. Statistics shows till May 2019 the number of block chain enterprises in the Yangtze River Delta exceeded 3,400, where over 600 are located in Jiangsu Province, over 800 are located in Anhui Province, over 1,700 are located in Zhejiang Province, and over 200 are located in Shanghai [1].

However, with the continuous introduction of relevant national policies and the increasing application of block chains in SCF, it becomes a major concern how to study the impact of block chains on SCF, especially transport capacity SCF, how to manifest the block chain credit enhancement, 
and how would transport capacity SCF enabled by block chain affect the credit granting to SMEs.

Based on above topics, study in this paper is conducted in aspects of credit access, credit line, and credit supervision. In Section 2, the literature review to clarify the application of block chain in SCF is conducted, in Section 3, the influence of block chain on credit access from aspects of credit transmission attenuation and block chain credit enhancement is studied, in Section 4, the influence of the block chain on the credit line through the business self-compensation formed by income and the participation of credit insurance promoted by the block chain is analyzed, in Section 5, the influence of block chain on credit supervision by establishing the alliance chain is analyzed, and in Section 6, the whole paper is reviewed and outlook of next research is stated.

\section{Literature Review}

This paper studies the impact of block chain on credit granting in the context of transportation capacity SCF. Based on related topics, the literature review is divided into two parts: (1) block chain technology analysis, that is, to clarify the research direction and trend of block chain technology; (2) the application of SCF and block chain in SCF, namely, to clarify the development of SCF and the research needs of block chain in SCF, especially in transportation capacity SCF.

2.1. Block Chain Technology Analysis. The current academic research on the block chain technology itself is homogeneous, mainly including the interpretation of distributed ledger, super ledger, asymmetric encryption, consensus mechanism, smart contract, hash value, time stamp, tree authentication, Ethereum, Byzantine fault tolerance, and so on, from different perspectives [2-5]. With the development of block chain technology from theory to practice, some scholars began to study the classification of block chain, including public chain, alliance chain, and private chain or unlicensed block chain, open licensed block chain, and closed licensed block chain $[3,6]$. In the process of continuous practice, block chain technology related problems have also become the focus of research. Karagiannis et al. [4] pointed out that one of the main disadvantages of block chain networks is the poor performance of transaction latency, which makes it unsuitable for real-time applications. $\mathrm{Xu}$ et al. [7] pointed out that the security, scalability, and decentralization in the block chain cannot be satisfied at the same time, making it an impossible triangle. In the current mainstream block chain system, almost no one can achieve unlimited expansion [8]. Li et al. [9] elaborated on the existence of various common security vulnerabilities in the block chain, such as DDoS attacks, Trojan horse, hacker attacks on private accounts, and advertisement viruses. At the same time, many scholars have studied the attack recognized by more than half of the nodes in the block chain, namely, the " $51 \%$ security vulnerability" $[10,11]$. In the future, the research on block chain technology will develop towards increasing security, reducing deployment cost, establishing relevant standards of block chain, perfecting the legal system, and other aspects. The block chain policy will focus on two keywords: "development" and "supervision" [12]. The key technologies of supervision include transaction tracing technology, abnormal transaction detection technology, illegal behavior identification technology, and user identity speculation, and tracking technology [13]. Breakthroughs will be made in mainstream basic consensus algorithms and block chain extension technologies such as public chain, alliance chain, private chain, cross-chain, sidechain, sharding, BaaS, SaaS, lightning network, smart contract, security services, and solutions. At the same time, legalization of supervision, legalization of legislation, and legalization of risk management will also become the cornerstone of the improvement of block chain technology [14].

2.2. The Application of Block Chain in SCF. As far as block chain is concerned, there are mainly three types of researching applications in SCF at present.

The first type is the platform construction based on block chain. Liu et al. [15] constructed the framework of tobacco SCF service platform based on block chain technology and pointed out that the block chain platform uses intelligent algorithms to evaluate whether suppliers meet the loan requirements according to the minimum standard value of smart contract indicators. Li et al. [16] proposed a logistics finance implementation platform that supports block chain and takes it as an integrated solution to promote e-commerce retail logistics financing.

The second type is the improvement or innovation of SCF model based on block chain. Li et al. [17] used the block chain to generate smart contracts and improved the operation process of three SCF models, namely, advance payment financing, accounts receivable financing, and inventory pledge financing. Wang et al. [18] indicated an agricultural SCF model of "insurance + futures" based on block chain. Yang [19] outlined several innovative models of SCF based on block chain, including "block chain + documents," "block chain + transactions," "block chain + ecology," "block chain + bills," and "block chain + securitization."

The third type is the mechanism analysis of the impact of block chain on SCF. Zhang [20] analyzed the impact of block chain incentive mechanism on SCF from the perspective of game theory. Guo and Chen [21] analyzed the path of block chain technology to break through the "information islands" of SCF. Wang et al. [22] indicated the impact path of distributed ledger, smart contract, and decentralization of block chain technology on the three pain points of SCF risk, data gap, and information asymmetry.

Based on the literature review, the block chain technology has been constantly improved for more comprehensive application to practical scenarios, and the SCF has been continuously strengthened to expedite the application mode innovation, jointly promoting the integrated development of the block chain and SCF. However, from the perspective of 3 representing applications currently, the 
"warehouse" finance is still the main concern for block chain application such as inventory pledge financing with less attention paid to "transportation" finance. Meanwhile the current study of block chain influencing mechanism over SCF mainly focuses on the defects in SCF and the methods to overcome these defects by establishing block chain platforms in prevention against potential risks or the solution to information asymmetry by introducing decentralized features of the block chain, but less study is conducted concerning the nature of interinfluencing mechanisms among factors in SCF, meaning the final credit enhancement and granting by applying block chain into SCF, as the inborn advantage of such application. Few have proposed the multitier debt split by block chain technology, which can be ascribed to "credit enhancement," yet the further study of influence of such "credit enhancement" over final credit granting remains untouched. It is an important topic with less attention to combine transportation capacity supply chain with updated financing innovations such as block chain by sorting out the essence of the impact of block chain on the credit of transportation capacity SCF for the comprehensive application of inclusive financing to transportation capacity financing demands. The corresponding theoretical system is in urgent need for practical guidance, so the scope of application of transportation capacity SCF could be extended and challenges in highway transportation capacity could be removed.

\section{The Influence Mechanism of Block Chain on Credit Access}

Credit access involves the introduction of credit, by which the financial institutions shall make decisions whether to grant the credit after reviewing enterprises financial status.

\subsection{Attenuation of Credit Transmission in the Transportation} Capacity Supply Chain. The transportation capacity supply chain features multilevel subcontracting operations from top shippers to service integrators such as large third-party logistics, service intermediaries such as small third-party logistics, and dedicated lines and service providers such as fleets and drivers [23]. In the absence of credit, financial institutions would audit the transactions authenticity in contracts, orders, waybills, bills, and other information between SMEs and upstream enterprises while such SMEs are proposing financing demands. However, the credit is always weak for the noncore enterprise in supply chain upstream due to suspicion that arose from limit information, where the gradual transmission decrease in subcontracting plays the fundamental cause.

3.1.1. Intrinsic Attenuation Based on Transaction. Profits are produced in each node in the transportation capacity supply chain covering different service provisions, where the price obtained by different sectors remains unknown to each other. Defining the freight rate paid by the shipper to the large 3PL as $P_{1}$, the freight rate obtained by the small 3PL as $P_{2}$, the freight rate obtained by the special line as $P_{3}$, and the freight rate obtained by the fleet as $P_{4}$, there exists inequality as $P_{1}>P_{2}>P_{3}>P_{4}$ due to the dilution of profit retention on the price in same transaction, as a result for the future cash flow $M$ obtained by each node for these goods exists $M_{1}>M_{2}>M_{3}>M_{4}$. As acquisition ability of future cash flow is the evaluation basis for financial institutions to audit nodes credit, the better cash flow would lead to better debt paying ability and better credit, and vice versa; as a result for the credit capacity $\mathrm{C}$ of each node in the transport capacity supply chain, there exists $C_{4}<C_{3}<C_{2}<C_{1}$, where the credit of the shipper enterprise in the transportation capacity supply chain decreases in transactions through different nodes.

\subsubsection{Physical Attenuation Based on Loss. The trans-} portation capacity supply chain features interdriving mechanism among business flow, logistics flow, capital flow, and information flow. Cargo flow is generated from transaction, where the loss of cargo, such as damage, quantity decrease, and scattering, is inevitable in the transportation from shipper to the end user as the result of subcontracting and transshipment. The total freight would suffer deduction due to such cargo loss under the mode of freight rate and cargo volume settlement or due to cargo damage in the mode of vehicle and route settlement, which would lead to weaker cash flow acquisition ability. The cash flow acquisition ability would become even weaker with the increasing probability of cargo loss as a result of more frequent subcontracting, where the credit attenuation would become more obvious with the weaker cash flow acquisition ability caused by the greater probability of cargo loss as a result of multitier subcontracting through larger 3PLs to the terminal fleet.

3.1.3. Cognitive Attenuation Based on Deviation. As a result of information asymmetry, the financing enterprise as party with sufficient information would provide information like contract bills with worse authenticity than what is known to financial institutions as the party lacking information while contracts, orders, waybills, and bills are under auditing, which would lead to impaired information authenticity provided, resulting in the phenomenon of "bad money driving out good money." Therefore, poor cognitive evaluation credit is the direct result of the credit discount in contracts, bills, and other instruments when financial institutions choose to mitigate these risks while distinguishing transaction authenticity by financing enterprises; this is often the case when the upstream enterprises are noncore enterprises and the recognition of the credit represented by the information exchange is poor. The credit perception reduction caused by information deviation becomes the driving factor of credit attenuation.

3.2. Credit Enhancement of Block Chain with Transportation Capacity SCF. Multitier subcontracting is the reason for the transaction attenuation based on the intrinsic credit in the transportation capacity supply chain, and the treatment for 
physical attenuation based on loss lies in operation control. By shortening the chain based on decentralization character of block chain or reinforcing supply chain operation control by combining block chain to IOT and transportation management system, such attenuation might be relieved; however the "digital credit enhancement" by block chain for transportation capacity SCF is not fully demonstrated this way. Information asymmetry explains the cognitive attenuation based on deviation; the credit enhancement of transportation capacity SCF could be fully demonstrated by improving credit degree of financing enterprises based on block chain application, which is the focus in this paper.

\subsubsection{Upload Transaction Information to Block Chain.} By means of the hash value data, information such as contracts, orders, waybills, invoices, and tax bills collected offline can be uploaded and saved onto the block chain. Based on block chain technology merits such as distributed storage, nontamper data, encryption algorithm, etc., the transaction process traceability could be achieved knowing the "block interlocking, cross-verification" character of block chain, as shown in Figure 1.

A tree data structure of transactions processed by hashing produced by the collection of newly broadcasted transactions, such as financing events, would evolve into an information block, and such block would be only accepted by the other nodes when all transactions proved valid; then a permanent and transparent transaction record would be produced after automatically stamping on the block chain. Meantime the negotiated and formed contract terms between nodal enterprises would be written as small programs once programming conditions are met through the intelligent contract of the block chain and automatically take effect without the participation of a third party.

\subsection{2. "Digital Credit Enhancement" of Block Chain for} Transportation Capacity SCF. The transaction data related to the core enterprise such as shippers shall be explored by means of uploading the transaction information to the block chain concerning the special line as the main financing demand enterprises. At the same time, the transaction data are recorded and protected jointly by various participants, such as large 3PL and small 3PL through the block chain consensus mechanism, ensuring the consistency and authenticity of the transaction data in each participating node and avoiding the transaction data fraud behavior of a single node. By means of smart contract transaction data checking the authenticity of business data could be ensured and nodes could be endorsed; thus legitimacy and consensus of the chain data could be guaranteed and more credible signature check on the chain of transaction could be achieved; finally further credit guarantee for transaction data could be provided. The transaction data generated by multiparty consensus and endorsement cannot be tampered and is true and reliable; the precondition for such tampering is to tamper all ledger books by all participating nodes; otherwise no consensus in block chain could be achieved. The high cost of tampering transaction data could effectively reduce the risk of fraudulent transaction data in the transportation capacity supply chain; then the cognitive attenuation based on the deviation caused by information asymmetry could be relieved and reedit could be enhanced concerning contracts, orders, waybills, and invoices, which would lead to the realization of the "digital credit enhancement." The "digital credit enhancement" could also be achieved in another method, where by means of uploading data onto block chain the strong credit by the core enterprises could be delivered to tail end SMEs through supply chain network transmission system, and the understanding of finance companies by financial institutions could be deepened and credits of special line enterprises could be improved. Therefore, we can get the following results.

The credit influence mechanism by block chain on transportation capacity SCF1: By improving the authenticity of transactions and relieving the attenuation in credit transmission by core enterprises, the block chain could enable the realization of "digital credit enhancement" and increasing the credit access of financial institutions to small and microfinancing enterprises such as special line.

\section{Influence Mechanism of Block Chain on Credit Line}

Credit line is the amount of funds granted by financial institutions to SMEs such as special lines according to the credit evaluation of the latter. In the principle of repayment ensuring, commonly the line of credit shall be fixed by business self-compensation or credit guarantee (Table 1).

\subsection{Parameter Setting. Description of parameter setting is provided in Table 1.}

4.2. The Line of Credit for Business Self-Compensation. In the transportation capacity SCF, the special line enterprises become the demanding nodes of financing as a result of advance payments for traffic fees and oil consumption. When determining the line of credit, financial institutions shall not only consider the actual payments needed by financing enterprises to cover the traffic fees and oil consumption, but also consider the capital repayment ability of financing enterprises. Business self-compensation refers to the ability to repay through business income; considering the business authenticity risk the line of credit granted by financial institutions is usually the product of business income multiplied by a certain credit coefficient $K . K$ is the proportion of actual payment demands such as traffic fees and oil fees in the total cost in the transportation business; defining the business income generated by the financing enterprise as $M$, then the line of credit $L_{s}$ based on business self-compensation is as follows:

$$
L_{s}=M K
$$

where $K$ could be produced by statistics analysis of big data covering the freight rate $q^{*}$, the net transportation interest 


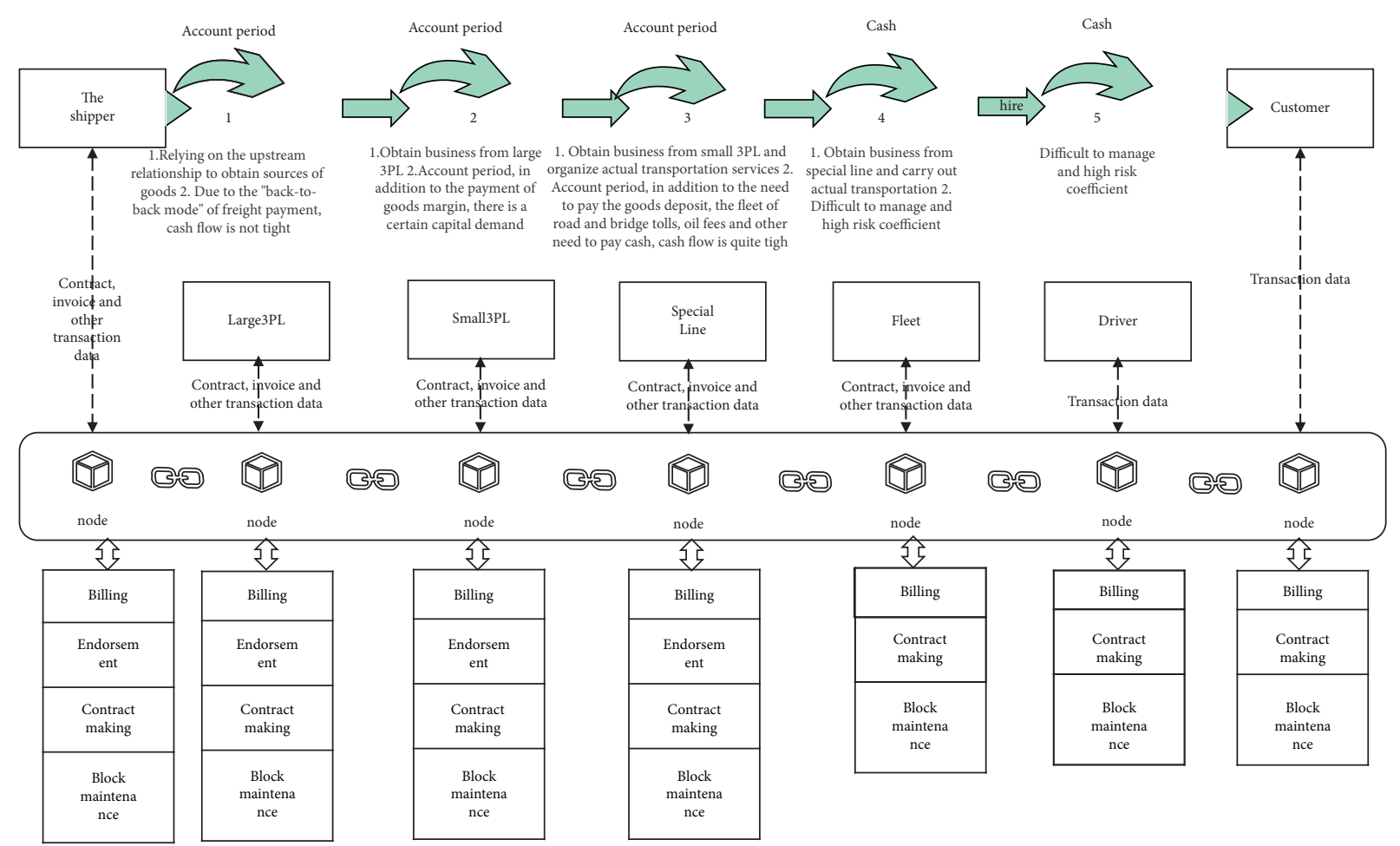

Figure 1: Application diagram of block chain in the transportation capacity supply chain.

rate $r$, the fuel consumption of 100 kilometers $\alpha$, unit diesel oil price $\gamma$, and the average road and bridge fee $\beta$, namely,

$$
K=\frac{(\alpha \gamma / 100)+\beta}{q^{*}(1-r)} .
$$

The business income $M$ could be determined by transportation volume $Q$, freight price $q$, and freight distance $s$, namely,

$$
M=Q q s .
$$

As a random variable, the transportation volume often obeys a normal distribution [24, 25]. According to the mean and variance of the historical transportation volume of financing enterprises, the future transportation volume could be estimated. Transportation unit price $q$ could be obtained from sample transportation unit price $q^{*}$, while freight distance $s$ could be estimated from the historical GPS big data of the financing enterprise.

Combined with the above formula, the line of credit $L_{s}$ for business self-compensation could be refined as follows:

$$
L_{s}=Q q s \frac{(\alpha \gamma / 100)+\beta}{q^{*}(1-r)} \text {. }
$$

It is indicated in equation (4) that the line of credit based on business self-compensation is mainly affected by the credit coefficient $K$ and transportation volume $Q$; the former is generated from the authenticity of business income, while the latter is from the authenticity of historical transportation volume, and certain data error is inevitable as a result of statistics in the latter. $K$ could be regarded constant in certain transportation mode or service sectors as shown in statistics; thus the space for accuracy improvement for $\mathrm{K}$ is little.

4.3. The Line of Credit for the Credit Guarantee. For financial institutions, the risk of credit under credit guarantee is usually relatively controllable. Guarantee enterprises are often the core enterprises in the supply chain. Credit could be granted to SMEs with poor credit such as special lines through the strong credit guarantee of core enterprises. The size of the line of credit in this mode mainly depends on the size of the line of credit guarantee and the credibility of the guarantee. Strong credibility and guarantee amount means solid credit, small probability of default, and low risk, while the guarantee amount under weak credibility means worse credit, high probability of default, and high risk. Thus, the credibility of credit guarantee is the key factor to line of credit. Quantitative analysis could be applied by transforming measuring credibility to measuring default probabilities. Defining the credit guarantee limit of the core enterprise as $V$ and the default probability of the core enterprise as $p$, then the credit line $L_{c}$ based on the credit guarantee can be expressed as

$$
L_{c}=V(1-p) \text {. }
$$

The amount of credit guarantee for financing enterprises by core enterprises often depends on the amount of business conducted between both. The income of financing enterprises is the expenditure of core enterprises. For this reason, $V$ is determined to be equivalent to equation (3), namely, 
TABle 1: Parameter setting table.

\begin{tabular}{|c|c|c|}
\hline Parameter category & $\begin{array}{c}\text { Parameter } \\
\text { symbol }\end{array}$ & Parameter definition \\
\hline \multirow{13}{*}{$\begin{array}{l}\text { Business self- } \\
\text { compensation }\end{array}$} & $L_{s}$ & Credit line based on business self-compensation (Yuan) \\
\hline & $L_{s}^{*}$ & Actual credit line based on business self-compensation (Yuan) \\
\hline & $\begin{array}{l}L_{s} \\
M\end{array}$ & Business revenue, the future income of the financing enterprise, reflects the solvency (Yuan) \\
\hline & $K$ & Credit factor: the ratio of credit line to business revenue \\
\hline & $K^{*}$ & Actual credit factor judged by financial institutions \\
\hline & $q^{*}$ & Unit freight rate based on big data sample statistics (Yuan/ton/km) \\
\hline & $r$ & Net interest rate of transportation \\
\hline & $\alpha$ & $\begin{array}{l}100 \mathrm{~km} \text { fuel consumption (such as } 9.6 \text { m models, fuel consumption } 25 \mathrm{~L} / 100 \mathrm{~km} ; 13.5 \mathrm{~m} \text { model, } \\
\text { fuel consumption } 28-30 \mathrm{l} / 100 \mathrm{~km} \text { ) }\end{array}$ \\
\hline & $\beta$ & $\begin{array}{l}\text { Road and bridge fee per kilometer (for example, the average road and bridge fee for a 9.6-meter } \\
\text { model is } 1.8-2.0 \text { yuan/kilometer; average road and bridge fee for } 13.5 \mathrm{~m} \text { models: } 2.4-2.5 \text { yuan/ } \\
\mathrm{km} \text { ) }\end{array}$ \\
\hline & $\gamma$ & Diesel oil unit price (yuan/liter) \\
\hline & Q & Expected volume of financing enterprises (ton) \\
\hline & $q$ & Average freight rate of financing enterprises (yuan/ton-km) \\
\hline & $s$ & Expected transportation distance of financing enterprise $(\mathrm{km})$ \\
\hline \multirow{22}{*}{$Y$} & $u$ & Credit line based on credit guarantee (Yuan) \\
\hline & $L_{c}^{*}$ & The actual line of credit granted based on the credit guarantee (Yuan) \\
\hline & $\stackrel{c}{V}$ & The credit guarantee line of the core enterprise (Yuan) \\
\hline & $p$ & The default probability of the transportation core enterprise \\
\hline & $p^{*}$ & $\begin{array}{c}\text { The actual default probability of the transportation core enterprise judged by financial } \\
\text { institutions }\end{array}$ \\
\hline & $p_{i}$ & The default probability of the $i$-th transportation core enterprise \\
\hline & $x_{i j}$ & The value of the $j$-th financial indicator of the $i$-th transportation core enterprise \\
\hline & $y_{i}$ & The $i$-th quantile of default probability of transportation core enterprise \\
\hline & $i=1,2,3, \ldots, n$ & The number of sample transportation core enterprises \\
\hline & $m$ & The number of financial indicators \\
\hline & $\tilde{p}_{i}$ & The sample default probability of the $i$-th transportation core enterprise \\
\hline & $\frac{1}{x_{i j}}$ & The sample value of the $j$-th financial indicator of the $i$-th transportation core enterprise \\
\hline & $\frac{i t}{y_{i}}$ & Sample value of the $i$-th quantile of default probability of transportation core enterprise \\
\hline & $a$ & Logistic model parameters \\
\hline & $b_{j}$ & Logistic model parameters \\
\hline & $\varepsilon_{i}$ & Logistic model random error term \\
\hline & $\sigma^{2}$ & The variance of the random error term \\
\hline & $r_{b i}$ & The actual interest rate of the $i$-th sample enterprise bonds \\
\hline & $r_{f}$ & The interest rate of treasury bonds of the corresponding period \\
\hline & $r_{n i}$ & The nominal interest rate of the sample enterprise bonds \\
\hline & $r_{t}$ & The interest tax rate of the sample enterprise bonds \\
\hline & $z$ & The default loss rate of the sample enterprise bonds \\
\hline
\end{tabular}

$$
\mathrm{V}=\text { Qqs. }
$$

Substituting (6) into (5), the credit line $L_{c}$ of credit guarantee can be refined as follows:

$$
L_{c}=Q q s(1-p) \text {. }
$$

It is indicated in equation (7) that the line of credit based on credit guarantee is mainly affected by the transportation volume $Q$ and the probability of default $p$; certain data error is inevitable as a result of statistics of historical traffic volume, while the latter is based on financial factors. The lower the probability of default, the larger the value of $L_{c}$ of credit line.

4.4. Block Chain Has Increased the Line of Credit for Transportation Capacity SCF. According to articles 4.1 and 4.2, both the line of credit based on business self-compensation and the credit line of credit guarantee are affected by business authenticity. The former is affected by the authenticity of revenue and historical transportation volume, while the latter is affected by the authenticity of historical transportation volume and the regulatory of default probability. The repayment ability of financing enterprises recognized by financial institutions would be reinforced as a result of business income authenticity enhancement so the actual credit coefficient $K^{*}$ shall be greater than the credit coefficient $K$ calculated by the sample big data, resulting in the actual credit line $L_{s}^{*}$ greater than the calculated credit line $L_{s}$, so the increase of credit line based on business selfcompensation could be achieved.

The enhancement of the authenticity of historical transportation volume would lead to better future transportation volume prediction accuracy, but the future transportation volume as well as line of credit $L_{c}$ would not be increased. Meanwhile through the introduction of 
authenticity of historical traffic data guarantee by the block chain and the introduction of credit insurance, the probability of default $p$ or the superposition of the insurance amount could be substantially reduced, so the line of credit $L_{c}$ based on the credit guarantee could be increased; the details are as follows.

\subsubsection{Use Block Chain to Increase the Participation of Credit} Insurance. Credit insurance refers to the behavior of financial institutions transferring risk via insurance at the awareness of risks in small, medium, and micro financing enterprises. Credit insurance is divided into two modes: in mode one the financial institutions insure themselves by paying the premium firstly and then transferring the same to financing enterprises; in mode two financial institutions order financing enterprises to provide a guarantee, and financing enterprises provide a guarantee to financial institutions by borrowing the credit from the insurer [6].

In transportation capacity supply chain, the transaction information of financing enterprises could only be collected by neighboring upstream and downstream contracts, invoices, statements, etc., due to multitier subcontracting; in order to lower the insurance premiums or obtain high insurance amount, financing businesses are inclined to withhold adverse information or conduct joint conspiracy together with upstream and downstream enterprises, which would lead to not only the increasing difficulties for insurers to obtain true information, but also severe loss on insurers once such enterprises got insured; then the insurers would be intimidated by the increasing default rate and loss rate, as shown in Figure 2. In combination with 3.1, the block chain trading platform produces an execution suggestion bearing the information of contracts, orders, waybills, receipts, statement, and invoices and sends the same to each endorsement node by uploading transaction information onto the block chain. In each endorsement node the smart contract is independently processed and the execution response with signature is produced. These responses would be checked once enough executable responses are sent to the block chain platform. A transaction containing these responses would be produced internally and submitted to the sorting service nodes once such verification passed. The sorting node receives transactions from the block chain platform, sorts requests by a block, validates the encapsulation to produce new blocks, and broadcasts blocks to the master node. The master node synchronizes the block information with the billing node and the endorsement node for verification. Blocks verified by more than $50 \%$ of the total number of nodes would be added to the existing block chain to complete the verification of the transaction information, as shown in Figure 3.

The upload historical information serves as credit data which would reduce the risk of fraudulent claims and insurance, removes problems in trust, and enhances the insurance credit.

\subsubsection{Increase the Credit Line through Credit Insurance.} By introducing credit insurance, financial institutions take the amount of potential loss at default occurrence as the insurance object, and the insurer estimates the probability of default according to the real transaction data recorded in the block chain and makes flexible quantitative charging. For this reason, financial institutions could reduce the default probability $p$ through insurance guarantee, the actual default probability $p^{*}$ is less than the default probability $p$ calculated based on the financial indicators, and the actual line of credit $L_{c}^{*}$ is greater than the calculated line of credit $L_{c}$, resulting in that line of credit could be increased based on credit guarantee.

By introducing credit insurance, financing enterprises take the repayment ability generated by future business volume as the insurance object, while the insurer estimates the future business growth ability and sets the corresponding premium according to the historical transportation volume data of financing enterprises in the chain. Financial institutions could increase the credit line $L_{c}^{*}$ to certain level, but always within the insurance limit set by the financing enterprises, and $L_{c}^{*}$ shall exceed the original calculated line of credit $L_{c}$ after superimposing, resulting in that line of credit based on credit guarantee could be increased. In doing this we conclude the following.

The credit influence mechanism by block chain on transportation capacity SCF2: By verifying the transaction behaviors in the transportation capacity supply chain, introducing credit insurance, and improving the cognition of the repayment ability of enterprises, the block chain could help to increase the credit granted by financial institutions to SMEs such as special lines.

\section{Influencing Mechanism of Block Chain on Credit Supervision}

In China the financial industry is performing under strict supervision, all financial activities must be regulated, and the recent suspension of Ant Group's A + $\mathrm{H}$ share listing is the expression of such strictness by the system. Credit supervision involves the credit access and limit determination before setting closed-loop supervision over the specific lending process and the use of funds.

\subsection{Alliance Chain Establishment under Closed-Loop} Supervision. Closed-loop regulation contains trading closed-loop, delivery closed-loop, and capital closed-loop. Transaction closed-loop involves the comparison and verification of contracts, documents, and invoices in each link of the supply chain where the financing enterprise is located with a complete transaction logic. Delivery closed-loop involves the realization of the logistics execution from the intermediate links of the financing enterprises such as the shipper, with special line to the delivery of the final customer. Capital closed-loop refers to the entire closed-loop of capital circulation in which the credit of financial institutions can be extended from the financing enterprises, such as the special line to the downstream fleet and drivers, and the capital would return to the shippers after final receiving of cargo by customers; finally the income of the financing enterprises would reimburse the circulation. It is indicated 


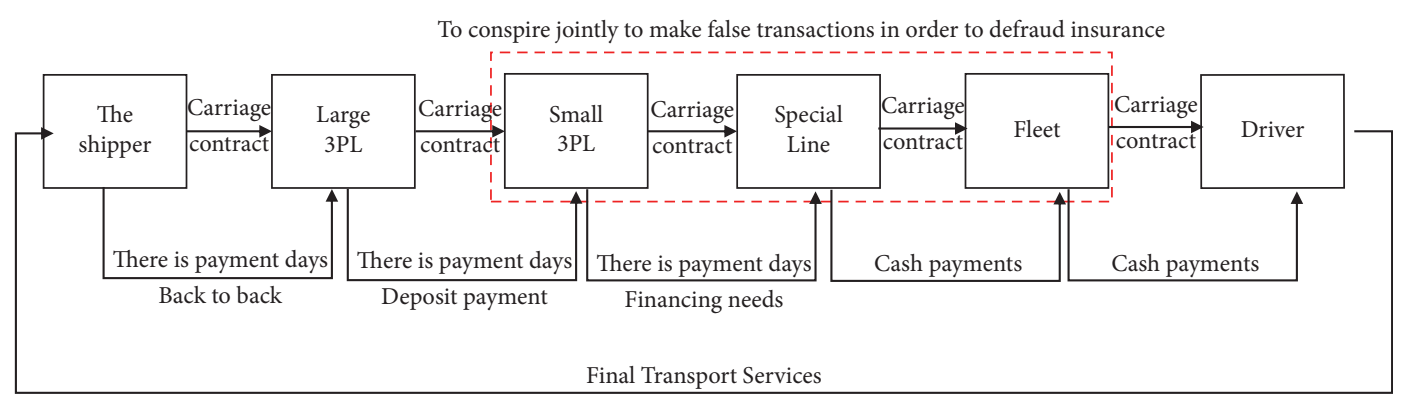

Figure 2: Collusive behavior in the transportation capacity supply chain.

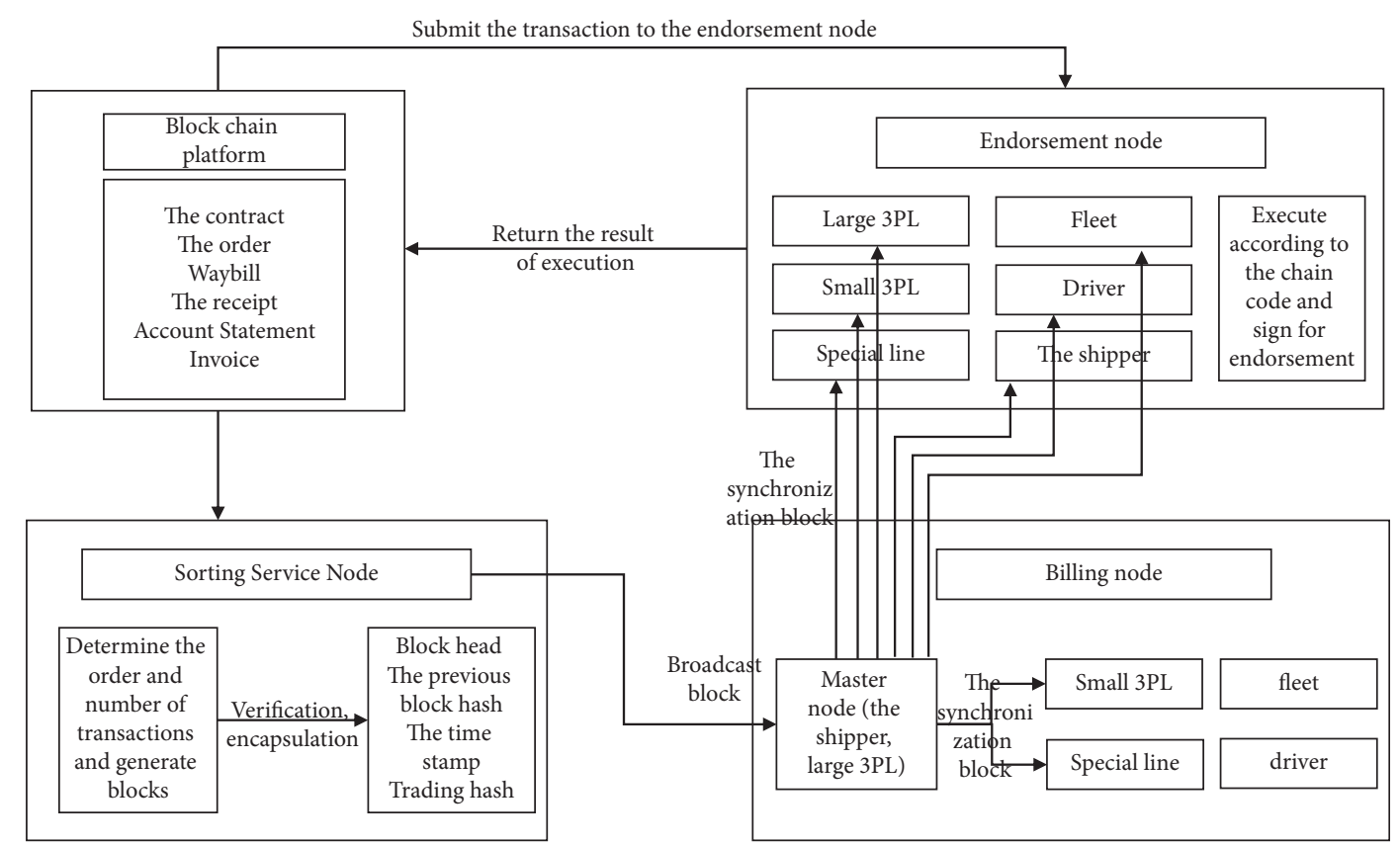

FIGURE 3: Verification process of block chain on transaction behavior of transportation capacity supply chain.

that the transparency and information control required by visible trading, visible delivery, and traceable capital is the key to closed-loop regulation.

The alliance chain is between the private chain and the public chain of the block chain. It not only contains the block chain features such as collective maintenance, information transparency, traceability, and being tamper-proof, but also contains the controlling ability over the participation, qualification, and data by the member nodes, making the supervision relatively controllable. The alliance chain could be established to meet the closed-loop supervision requirements upon the financing credit being granted to transportation capacity supply chain. The details are as follows.

As shown in Figure 4, the smart contract public key of the alliance chain is used to encrypt the transaction information, delivery information, capital flow information, and other matters in the financial activities of the transportation capacity supply chain. Each node of the alliance chain uses its private key to sign the verified information and broadcasts it to produce the block for verification. Each node calls the ledger to obtain relevant data and verify the validity of the signature. Once more than $50 \%$ of the nodes reach a consensus, the new block would be produced by being broadcasted again, and the ledger would be updated to the alliance chain by linking to the header of the previous block. Otherwise, shall the consensus node be lower than $50 \%$, two mutually disjoint union chains would be built, the bifurcate block competition force of both would be compared in subsequent block linking, and the chain with stronger competition would be extended by further linking; consequently the longest chain would be taken as main chain blocks in entire network and the uniqueness of data could be protected [26]. At the same time, data permissions are set for each node. Financial institutions enjoy high level access to the upstream and downstream contracts, documents, bills, goods, and fund status related to the business carried out by financing enterprises, while other nodes are in procession of baseline access to relevant information derived from neighboring upstream and downstream. In this way, the transparency and traceability of information could be guaranteed, the requirements by financial institutions for credit supervision could be met, and the original business environment could be maintained to ensure the interests of each node. 


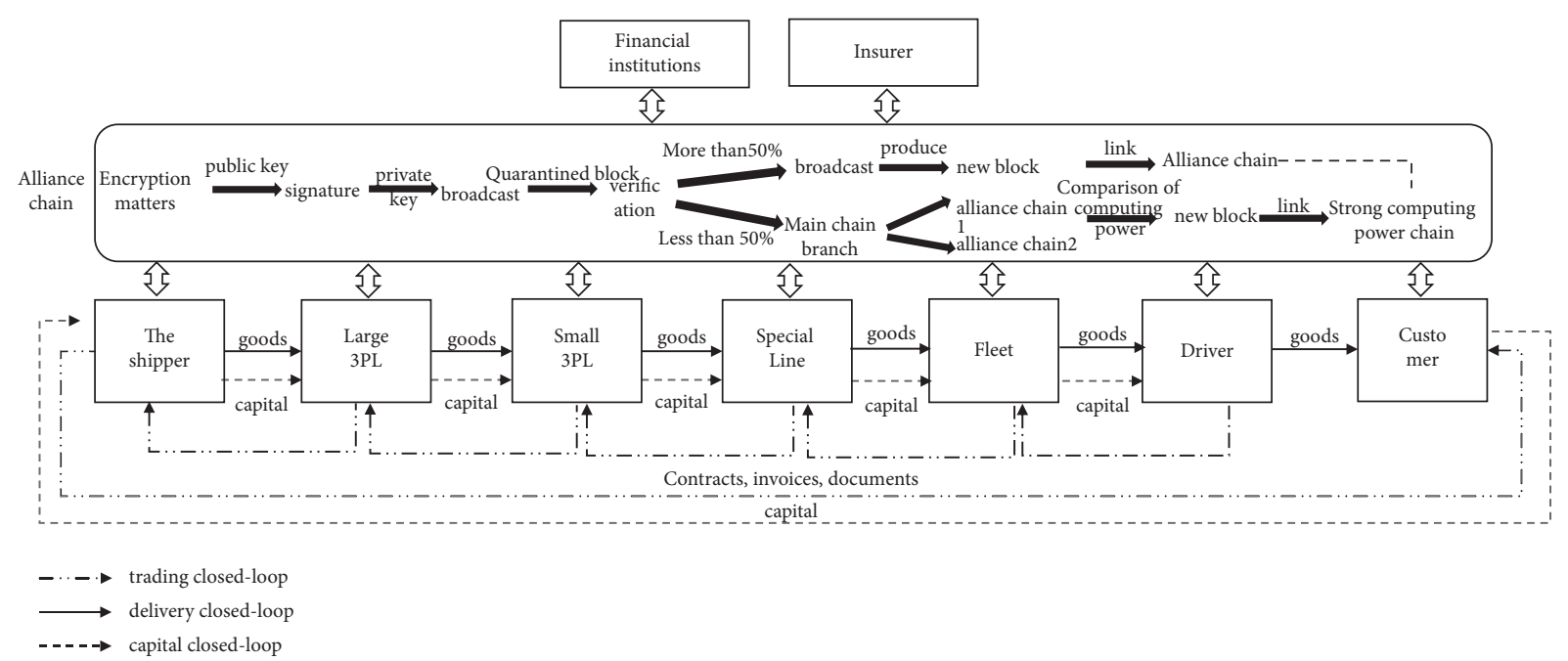

FIGURE 4: Transportation capacity SCF alliance chain.

\subsection{Block Chain Objectifies the Financial Debt Structure of the Transportation Capacity Supply Chain. Through the estab- lishment of the alliance chain, the objectivity of the structure of creditor's rights and debts could be realized based on the cross-verification of business and the dynamic matching of operating documents and debt.}

5.2.1. Cross-Validation of Business and Assets. The assets in the transportation capacity supply chain mainly contain vehicles, cargos, and receivables. The cross-validation between the business of consignor nodes and assets is mainly reflected in the cross-validation between product sales business and cargos in circulation. The cargo information in circulation could be fixed into the chain of the shipper's sales contract and delivery documents, which cannot be changed. Cross-verification can be realized by matching the relevant goods information of other nodes. For large 3PL nodes and small 3PL nodes, the cross-validation of node business and assets is mainly reflected in the cross-validation of transportation business and receivables. The business income would be predictable after collection of freight rate, freight distance, and transportation volume information on the alliance chain so the cross-validation could be realized. With special line node, fleet node, and driver node, cross-validation of business and assets is mainly reflected in business documents and vehicles. The business documents collected by the alliance chain are immutable, so the vehicle information identified by the documents could be matched to the vehicle information of the actual feedback track data, fuel consumption data, and bridge toll data for cross-verification.

\subsubsection{Dynamic Matching of Operating Documents and Debt} Relationship. Contracts, invoices, and other operating documents exist at each node of the transportation capacity supply chain. As the voucher of cargo delivering, power and obligation transferring, and creditor and debt relationship, the operation document is the key to data collection and cross-verification in alliance chain. The smart contract is the passage to dynamic data matching simultaneously and the automatic response to the requirements of the contract. Once the driver uploads the receipt after delivering the cargo, the debt receivable of the fleet to the special line and the debt payable of the special line to the fleet would be automatically recorded according to the contract. Once the payment is made on the special line, the debtor-creditor relationship would be automatically recorded as completed, and the debtor-creditor relationship in the whole transportation capacity supply chain would be dynamically updated. Moreover, the transparency of receivables and payables would be enhanced based on distributed ledger of block chain data, which would promote the intersupervision among nodes over debt relationship and the dynamic updating of such information, resulting in that a good debt environment could be the company to the alliance chain.

The real business and dynamic debt relationship matching would lead to the establishment of better accuracy and immutability of debt structure in the transportation capacity supply chain finance, providing a solid foundation for the financial institutions for effective credit supervision.

5.3. Automatic Governance of Financial Capital Flow of Transportation Capacity Supply Chain by Block Chain. Upon the utilization of alliance chain, the autonomous capital flow in the transportation capacity supply chain could be realized by unifying financing amount management and the automatic execution of smart contracts.

\subsubsection{Unified Management of Financing Amount.} According to 5.2, financial institutions could easily control the transaction dynamics of the whole supply chain through the objectification of the creditor and debt structure of each node in the transportation capacity SCF, which is suitable for the unified management of financing amount. The final financing demand of the special line enterprises lies in the payment of road and bridge fees and oil fees, etc. Upon the termination of the rights and obligations in the 
subcontracting at various levels, the debt relationship between the special line enterprises and the downstream enterprises would be objectified and funds would be allocated to the drivers. On the one hand, the execution of the final logistics and completion of the closed-loop delivery of logistics services could be ensured to satisfy customers. On the other hand, by means of targeting payment of funds and fixing purpose of the loan, the unified management of the financing amount would be realized in line with the supervision requirements of China Banking and Insurance Regulatory Commission Office on the flow of funds in financial activities.

5.3.2. Smart Contracts Are Executed Automatically. Instead of posttransaction checking upon multiple parties' approval, terms for logistics services and capital flows between special line and fleet nodes are programmed into a smart contract in advance and turned into a transaction execution agreement. The smart contract would send a notification to both parties and require the special line node to deliver the cash flow at a certain time with the settlement result ordering the cash flow paid by the special line node to the fleet node. When it is time to honor the payment, the smart contract would automatically execute the allocation of funds from the special line account to the fleet account and broadcast the same to the whole network; the same would be stored in the relevant transaction information in the alliance chain. Shall the funds not be disbursed on time, the same would also be stored in the alliance chain without tampering. The financial institutions and other nodes of the transport supply chain would be informed of such failure of disbursement and would expedite the adjustment of credit assessment and qualification authority of this node accordingly.

Directional payment of financing amount and automatic triggering of fund allocation is the precondition for automatically controlling capital flow in transportation capacity SCF, which is the ultimate symbol of credit supervision by financial institutions. For this, we can conclude the following.

The credit influence mechanism of block chain on transportation capacity SCF3: Through the establishment of the alliance chain, the objective structure of the financial debt of the transportation capacity supply chain and the autonomy of the capital flow direction could be formed, and the credit supervision of the transaction closed-loop, delivery closed-loop, and capital closed-loop could be realized.

\section{Conclusion}

In this paper by referring to the SCF supported by block chain and other technologies as next hot topic in the new financial field, firstly through the literature review, current research on the application of block chain in SCF is analyzed, indicating the fact that the application of block chain in SCF is mainly from the perspective of "warehouse" finance, and there is almost no application from the perspective of "transportation" finance. Meanwhile the research on the impact of block chain on SCF is mainly to address problems in SCF by employing technologies instead of analyzing the essential impact on each link in SCF. From the perspective of "transportation" finance, the intrinsic attenuation of transactions reflected by the dilution of price by profit retention, the physical attenuation of goods loss under subcontracting and transferring, and the cognitive attenuation of credit evaluation under information asymmetry are firstly analyzed in this paper. Furtherly, the mechanism of strong credit of core enterprises being transmitted to the end SMEs by block chain based on the transportation capacity supply chain network is demonstrated, and the first credit influence mechanism of block chain on transportation capacity SCF is concluded. Then the quantitative analysis of the credit line evaluation method under business self-compensation and credit guarantee is conducted in the paper for further elaboration on the utilization of block chain in solving the trust problem, improving the participation degree of credit insurance, and enhancing the credit line. Thus, the second credit influence mechanism of block chain on transportation capacity SCF is concluded. Finally, through the establishment of the alliance chain under closed-loop supervision, the cross-verification of business and assets could be achieved, the dynamic matching of operating documents to debts could be formed up, and the unified management of financing amount and the automatic execution of smart contracts could be built; thus the third credit influence mechanism of block chain on transportation capacity SCF is concluded.

Analysis regarding essence of blockchain's impact on transportation capacity SCF in stages and steps is conducted in this paper with the following innovations:

(1) Researching perspective innovation. Taking "transportation" finance as the research object, which contains substantial financing demand and was difficult to cover with traditional credit, then the mechanism is expounded from the perspective of blockchain credit enhancement.

(2) Innovation of researching methods. Multitier and indetailed demonstration is conducted on the influencing mechanism by block chain on transportation capacity SCF from the three aspects of credit access, credit line, and credit supervision, and the influencing path is described as the support for the promotion and implementation of inclusive finance in the demand for transportation capacity finance.

(3) Researching idea innovation. The 2 calculation models of credit line based on business self-compensation and credit line based on credit guarantee are proposed, and the influence of block chain on both is analyzed, respectively, which provides reference for financial institutions to make credit decision in certain degree.

In addition, in this paper the quantitative analysis is applied only to the credit line linking analysis as small part while the theoretical demonstration is applied to the impact mechanism of block chain on transportation capacity SCF 
credit as major part; apparently the quantitative analysis is not sufficient in this paper. Further statistical demonstration or case analysis needs to be conducted before transforming above influencing mechanism into a practical application (Such as Wang et al. [27]). At the same time, it remains to solve in further researching the realization of automatic collection of original data as ensuring source data authenticity (such as JR/T 0193-2020, financial application of blockchain technology-evaluation rules).

\section{Data Availability}

The data were obtained from the specific practice of the enterprise, with specific reference to China's Internet of Things + Supply Chain Finance White Paper (2020) (https://info.10000link.com/zhiku/book_details.aspx?id= 49).

\section{Conflicts of Interest}

The authors declare that they have no conflicts of interest.

\section{References}

[1] M. Zhu, "Research on the mechanism of application of block chain technology to industrial chain collaborative innovation," Journal of Harbin University, vol. 9, 2020.

[2] Z. Fang, X. Wang, and R. Jian, "The development trend and strategic application of block chain technology-based on literature perspective and practical level research," Management World, vol. 12, 2018.

[3] H. T. M. Gamage, H. D. Weerasinghe, and N. G. J. Dias, “A survey on blockchain technology concepts, applications, and issues," SN Computer Science, vol. 1, no. 2, p. 114, 2020.

[4] I. Karagiannis, K. Mavrogiannis, and J. Soldatos, "Block chain-based sharing of security information for critical infrastructures of the finance sector," Computer Security, pp. 226-241, 2019.

[5] S. Zeng, R. Huo, and T. Huang, "Survey of block chain: principles, proxess and application," Journal of Communication, vol. 41, no. 1, pp. 134-151, 2020.

[6] Z. Jiang, "Credit guarantee insurance: "growth point" or "tipping point" in the industry," Insurance Theory and Practice, vol. 7, 2020.

[7] D. Xu, Y. Zhang, and D. Zhang, "Development trend and application analysis of block chain with 5G," Telecommunication Science, vol. 2, 2020.

[8] C. Pan, Z. Liu, Liu Zhen, and Long Yu, "Research on scalability of block chain technology: problems and methods," Journal of Computer Research and Development, vol. 55, no. 10, pp. 2099-2110, 2018.

[9] X. Li, P. Jiang, T. Chen, X. Luo, and Q. Wen, "A survey on the security of blockchain systems," Future Generation Computer Systems, vol. 107, pp. 841-853, 2020.

[10] M. Li, S. Shao, and Q. Ye, "Block chain-enabled logistics finance execution platform for capital constrained E-commerce retail," Robotics and Computer Integrated Manufacturing, vol. 65 , pp. 10-65, 2020.

[11] T. Bhogal and A. Trivedi, "Block chain technology and trade finance," International Trade Finance, pp. 10-02, 2019.

[12] X. Zhang, "2019 Block chain review and prospects," New Economy Weekly, vol. 1, 2020.
[13] J. Liu, L. Yan, and D. Wang, "A hybrid blockchain model for trusted data of supply chain finance," Wireless Personal Communications, vol. 4, 2021.

[14] J. Deng, "The rule of law on the block chain regulation," Journal of Hengyang Normal University (Social Science), vol. 41, no. 1, pp. 27-35, 2020.

[15] H. Liu, Z. Li, and N. Cao, "Framework design of financial service platform for tobacco supply chain based on block chain," Algorithms and Architectures for Parallel Processing, pp. 12-30, 2018.

[16] Z. Liu, Z. Zheng, S. Su, and Z. Zhaotian, "Problems in block chain and suggestions for counterplan," Bulletin of National Natural Science Foundation of China, vol. 34, no. 1, 2020.

[17] J. Li, S. Zhu, W. Zhang, and L. Yu, "Block chain-driven supply chain finance solution for small and medium enterprises," Frontiers of Engineering Management, vol. 7, pp. 7-29, 2020.

[18] J. Wang, R. Chan, Z. Zexu, and Z. Hanqing, "Agricultural supply chain finance innovation model design," China Market, vol. 25, 2020.

[19] Z. Yang, "Research on the innovation model of supply chain finance under the block chain framework," Logistics Scitech, vol. 4, pp. 153-155, 2020.

[20] L. Zhang, "Research on financial innovation of supply chains driven by block chain from the perspective of game theory," Economic Problems, vol. 4, pp. 48-54, 2019.

[21] J. Guo and C. Chen, "Research on the development and innovation of supply chain finance driven by block chain technology," Journal of Xi'an Jiaotong University, vol. 40, pp. 46-54, 2020.

[22] P. Wang, Li Yang, and Z. Huang, "Influence mechanism of block chain on supply chain finance," Journal of Heilongjiang University of Technology (Comprehensive Edition), vol. 20, no. 1, pp. 77-83, 2020.

[23] X. Chu, Y. Yubin, and J. Li, "Connotations and mode of transportation capacity supply chain," Traffic and Transportation, vol. 4, 2018.

[24] D. Zhang, R. Xie, S. Li, and R. Rongwu, "Research on optimization model of logistics park layout and its algorithm," Journal of Wuhan University of Technology, vol. 12, 2008.

[25] S. Zha, G. Yu, S. Huang, and F. Weiguang, "Dynamic layout of workshop facilities under uncertain requirements," Journal of Jilin University (Engineering and Technology Edition, vol. 47, pp. 1811-1821, 2017.

[26] J. Cui, W. Shengwen, and Y. Xin, "Research on the technical framework of smart grid data management from a consortium block chain perspective," Proceedings of the CSEE, vol. 38, pp. 37-43, 2020.

[27] C. Wang, H. Yu, and X. Sun, "Comparative research on the development layout of blockchain in Jangsu, Beijing, Shanghai, Guangdong and Zhejiang," Modern Management Science, vol. 39, pp. 97-108, 2021. 